\title{
Efficacy and Tolerability of the New Antiepileptic Drugs, I: Treatment of New-Onset Epilepsy: Report of the TTA and QSS Subcommittees of the American Academy of Neurology and the American Epilepsy Society
}

\author{
*Jacqueline A. French, $\nmid$ Andres M. Kanner, $\ddagger$ Jocelyn Bautista, $§$ Bassel Abou-Khalil, $\|$ Thomas

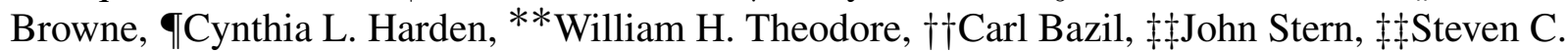
Schachter, †Donna Bergen, ${ }^{* *}$ Deborah Hirtz, \|Georgia D. Montouris, $§ \S$ Mark Nespeca, || ||Barry

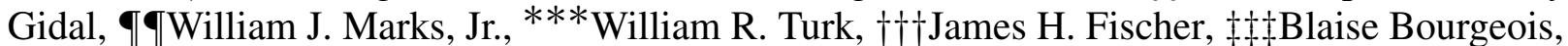
$\S \S \S$ Andrew Wilner, || || ||R. Edward Faught, Jr., ๆף $\mid$ Rajesh C. Sachdeo, ****Ahmad Beydoun, and $\dagger \dagger \dagger \dagger$ Tracy A. Glauser

\begin{abstract}
* University of Pennsylvania, Philadelphia, Pennsylvania; †Department of Neurological Sciences, Rush Medical College, Chicago, Illinois; $\$$ The Cleveland Clinic Foundation, Cleveland, Ohio; \$Vanderbilt University Medical Center, Nashville, Tennessee; //Boston University Medical Center, Boston, Massachusetts; 9 Weill Medical College of Cornell University, New York, New York; ** National Institutes of Neurological Disorders and Stroke, National Institutes of Health, Bethesda, Maryland; ††Columbia Presbyterian Medical Center, New York, New York; + Beth Israel Deaconess Medical Center and Harvard Medical School, Boston, Massachusetts; \$\$Children's Hospital, San Diego, California; ///School of Pharmacy and Department of Neurology, University of Wisconsin Hospital and Clinics, Madison, Wisconsin; 9 University of California San Francisco Epilepsy Center, San Francisco,

California; ***Nemours Children's Clinic, Division of Neurology, Jacksonville, Florida; $\dagger \dagger \dagger$ University of Illinois College of Pharmacy, Department of Pharmacy Practice and Neurology, Colleges of Pharmacy and Medicine, Chicago, Illinois; $+\neq+$ Department of Neurology, Children's Hospital, Boston, Massachusetts; \$\$\$Providence, Rhode Island; /II//Department of Neurology, University of Alabama School of Medicine, Birmingham, Alabama; 9 \ Department of Neurology, University of Medicine and Dentistry of New Jersey, New Brunswick, New Jersey; **** Department of Neurology, University of Michigan, Ann Arbor, Michigan; and $+\dagger+$ Department of Neurology, Children's Hospital Medical Center, Cincinnati, Ohio, U.S.A.
\end{abstract}

Summary: Purpose: To assess the evidence demonstrating efficacy, tolerability, and safety of seven new antiepileptic drugs [AEDs; gabapentin (GBP), lamotrigine (LTG), topiramate (TPM), tiagabine (TGB), oxcarbazepine (OXC), levetiracetam (LEV), and zonisamide (ZNS), reviewed in the order in which these agents received approval by the U.S. Food and Drug Administration] in the treatment of children and adults with newly diagnosed partial and generalized epilepsies.

Methods: A 23-member committee, including general neurologists, pediatric neurologists, epileptologists, and doctors in pharmacy, evaluated the available evidence based on a structured literature review including MEDLINE, Current Contents, and Cochrane Library for relevant articles from 1987 until September 2002, with selected manual searches up to 2003 .
Results: Evidence exists, either from comparative or dosecontrolled trials, that GBP, LTG, TPM, and OXC have efficacy as monotherapy in newly diagnosed adolescents and adults with either partial or mixed seizure disorders. Evidence also shows that LTG is effective for newly diagnosed absence seizures in children. Evidence for effectiveness of the new AEDs in newly diagnosed patients with other generalized epilepsy syndromes is lacking.

Conclusions: The results of this evidence-based assessment provide guidelines for the prescription of AEDs for patients with newly diagnosed epilepsy and identify those seizure types and syndromes for which more evidence is necessary. Key Words: New AEDs-New-onset epilepsy-Tolerability.

Accepted February 3, 2004. Approved by the Quality Standards Subcommittee on July 26, 2003. Approved by the Therapeutics and Technology Assessment Subcommittee on October 18, 2003. Approved by the Practice Committee on November 8, 2003, and by the Board of Directors on January 17, 2004. This article was published in the April 27, 2004 issue of Neurology. Copyright AAN Enterprises, Inc.

Address correspondence and reprint requests to Dr. Jacqueline A. French, The Neurological Institute, Hospital of the University of Pennsylvania, 3400 Spruce Street, Philadelphia, PA 19104, U.S.A. E-mail: frenchj@mail.med.upenn.edu

Drs. French and Tanner are co-chairpersons. 


\section{MISSION STATEMENT}

The Quality Standards and the Therapeutics and Technology Subcommittees of the American Academy of Neurology are charged with developing practice parameters for neurologists for diagnostic procedures, treatment modalities, and clinical disorders. The selection of topics for which practice parameters are used is based on prevalence, frequency of use, economic impact, membership involvement, controversy, urgency, external constraints, and resources required. This practice parameter summarizes the results of the evidence-based assessment regarding the efficacy, tolerability, and safety of seven new antiepileptic drugs (AEDs) in the management of newonset partial or generalized epilepsy. They are gabapentin (GBP; Neurontin), lamotrigine (LTG; Lamictal), topiramate (TPM; Topamax), tiagabine (TGB; Gabitril), oxcarbazepine (Trileptal; OXC), levetiracetam (LEV; Keppra), and zonisamide (ZNS; Zonegran). These AEDs were approved by the Food and Drug Administration (FDA) in the last 10 years. We recognize that these are antiseizure and not antiepileptic drugs. Nevertheless, we have decided to use in this assessment the term AED, given its widespread use.

\section{BACKGROUND AND JUSTIFICATION}

Almost two million people in the United States have epilepsy. A large epidemiologic study of Rochester, Minnesota, showed an age-adjusted epilepsy prevalence of 6.8/1,000 population, and the cumulative incidence through age 74 years was $3.1 \%(1,2)$. In the last 10 years, felbamate (FBM) and the seven AEDs cited earlier were approved by the FDA. The purpose of this assessment is to provide the clinician with evidence-based data on the efficacy, safety, and mode of use of these new AEDs, which can facilitate the choice of the appropriate drugs in the management the newly diagnosed partial seizure disorders and primary generalized epilepsy in children and adults.

The development of new AEDs for epilepsy over the last decade has been spurred by the fact that the available AEDs did not provide optimal care for patients with epilepsy. For many patients, all available options "failed," because either their seizures were not adequately controlled, or they were experiencing side effects. Prior to 1990, six major AEDs were available for the treatment of all forms of epilepsy. These included carbamazepine (CBZ), phenobarbital (PB), phenytoin (PHT), primidone (PRM), valproic acid (VPA), and, for absence seizures ethosuximide (ESM). The older drugs, although effective in patients with newly diagnosed epilepsy, share some characteristics. For example, older AEDs as a class have complex pharmacokinetics. Four of the six AEDs available prior to 1990 (PHT, CBZ, PB, and PRM) are hepatic enzyme inducers. Induction not only complicates combination AED therapy but also changes the internal
TABLE 1. Serious and nonserious adverse events associated with the new AEDs

\begin{tabular}{|c|c|c|}
\hline AED & Serious adverse events & $\begin{array}{c}\text { Nonserious } \\
\text { adverse events }\end{array}$ \\
\hline Gabapentin & None & $\begin{array}{l}\text { Weight gain, peripheral } \\
\text { edema, behavioral } \\
\text { changes }^{a}\end{array}$ \\
\hline Lamotrigine & $\begin{array}{l}\text { Rash, including } \\
\text { Stevens-Johnson and toxic } \\
\text { epidermal necrolysis } \\
\text { (increased risk for children, } \\
\text { also more common with } \\
\text { concomitant valproate use } \\
\text { and reduced with slow } \\
\text { titration); hypersensitivity } \\
\text { reactions, including risk of } \\
\text { hepatic and renal failure, } \\
\text { DIC, and arthritis }\end{array}$ & $\operatorname{Tics}^{a}$ and insomnia \\
\hline Levetiracetam & None & $\begin{array}{l}\text { Irritability/behavior } \\
\text { change }\end{array}$ \\
\hline Oxcarbazepine & $\begin{array}{l}\text { Hyponatremia (more common } \\
\text { in elderly), rash }\end{array}$ & None \\
\hline Tiagabine & Stupor or spike-wave stupor & Weakness \\
\hline Topiramate & $\begin{array}{l}\text { Nephrolithiasis, open-angle } \\
\text { glaucoma, hypohidrosis }{ }^{a}\end{array}$ & $\begin{array}{l}\text { Metabolic acidosis, } \\
\text { weight loss, language } \\
\text { dysfunction }\end{array}$ \\
\hline Zonisamide & $\begin{array}{l}\text { Rash, renal calculi, } \\
\text { hypohidrosis }^{a}\end{array}$ & $\begin{array}{l}\text { Irritability, } \\
\text { photosensitivity, } \\
\text { weight loss }\end{array}$ \\
\hline
\end{tabular}

This is not meant to be a comprehensive list but represents the most common adverse events, based on consensus of panel. Psychosis and depression are associated with epilepsy and occur in open label studies with all new antiepileptic drugs (AEDs). Although these side effects may appear more commonly with some drugs than with others, it is difficult to ascertain whether these relations are causal. Consequently, these side effects have been omitted from the table.

DIC, disseminated intravascular coagulation.

${ }^{a}$ Predominantly children.

hormonal milieu in possibly important ways. Intrinsic compounds, such as sex steroids and vitamin $\mathrm{D}$, are hypermetabolized. This can lead to reproductive dysfunction and osteopenia (3). Enzyme-inducing AEDs produce important interactions with many commonly used medications, such as warfarin, oral contraceptives, calcium channel antagonists, and chemotherapeutic agents, to name a few (4). VPA, in contrast, is a potent hepatic inhibitor. Controversy exists about the impact of VPA on the hormonal milieu $(5,6)$, and inhibition leads to important drug interactions with AEDs as well as with other classes. The newer agents are involved in many fewer drug interactions. Many of the newer agents have little, if any, effect on the CYP450 enzyme system and other metabolic pathways $(7,8)$.

Tables 1 through 4 provide a listing of serious and nonserious adverse events, common drug-drug interactions, effects of comorbid conditions, and pharmacokinetics for the drugs discussed in this parameter.

Recent studies $(9,10)$ indicated that patients with newly diagnosed epilepsy can be categorized into those who are treatment responsive or treatment resistant. Approximately two thirds of patients will become seizure free with 
TABLE 2. Common drug-drug interactions associated with the new antiepileptic drugs (AEDs)

\begin{tabular}{|c|c|c|c|c|c|c|}
\hline AED & Oral contraceptives & Warfarin & Other agents & $\begin{array}{l}\text { Enzyme } \\
\text { inducer? }\end{array}$ & $\begin{array}{l}\text { Enzyme } \\
\text { inhibitor? }\end{array}$ & Clinical notes \\
\hline Gabapentin & $(-)$ & $(-)$ & $\begin{array}{l}\text { Modest decrease in } \\
\text { gabapentin bioavailability } \\
\text { with Maalox-TC }\end{array}$ & $(-)$ & $(-)$ & $\begin{array}{l}\text { No known interactions with other } \\
\text { AEDs }\end{array}$ \\
\hline Lamotrigine & $\begin{array}{l}(+) \text { decrease in lamotrigine } \\
\text { serum concentrations by } \\
\text { oral contraceptives }\end{array}$ & $(-)$ & & $(+/-)$ & $(-)$ & $\begin{array}{l}\text { Modest induction of glucuronidation } \\
\text { with slight decrease in valproic } \\
\text { acid plasma levels }(25 \%) \text { noted. } \\
\text { Interactions with cytochrome } \\
\text { p450 isozymes not seen }\end{array}$ \\
\hline Levetiracetam & $(-)$ & $(-)$ & & $(-)$ & $(-)$ & $\begin{array}{l}\text { No known interactions with other } \\
\text { AEDs }\end{array}$ \\
\hline Topiramate & $\begin{array}{l}(+) \text { dose-dependent }(>200 \\
\text { mg/d) decrease in ethinyl } \\
\text { estradiol serum } \\
\text { concentrations }\end{array}$ & $(-)$ & $\begin{array}{l}\text { Modest increase in } \\
\text { haloperidol serum } \\
\text { concentrations. Modest } \\
\text { decrease in lithium serum } \\
\text { concentrations. Modest } \\
\text { decrease in digoxin serum } \\
\text { concentrations }\end{array}$ & $(+/-)$ & $(+)$ & $\begin{array}{l}\text { Modest, dose-dependent induction } \\
\text { of CYP } 3 \text { A4 may reduce } \\
\text { effectiveness of oral } \\
\text { contraceptives. Inhibition of CYP } \\
\text { 2C19 may result in increases in } \\
\text { phenytoin plasma concentrations. }\end{array}$ \\
\hline Tiagabine & $(-)$ & $(-)$ & $\begin{array}{l}\text { No interaction seen with } \\
\text { erythromycin }\end{array}$ & $(-)$ & $(-)$ & $\begin{array}{l}\text { Potential for protein-binding } \\
\text { displacement (clinical relevance } \\
\text { unclear) }\end{array}$ \\
\hline Oxcarbazepine & $\begin{array}{l}(+) \text { decrease in ethinyl } \\
\text { estradiol serum } \\
\text { concentrations }\end{array}$ & $(-)$ & $\begin{array}{l}\text { Modest decrease in felodipine } \\
\text { serum concentration. } \\
\text { Modest decrease in } \text { MHD }^{\mathrm{a}} \\
\text { concentrations after } \\
\text { verapamil administration. } \\
\text { No interaction seen with } \\
\text { erythromycin }\end{array}$ & $(+/-)$ & $(+)$ & $\begin{array}{l}\text { Modest, dose-dependant induction } \\
\text { of CYP 3A4 Possible induction of } \\
\text { glucuronidation, with reduced } \\
\text { plasma concentrations of } \\
\text { lamotrigine noted. Inhibition of } \\
\text { CYP 2C19 may result in increased } \\
\text { phenytoin or phenobarbital } \\
\text { plasma concentrations }\end{array}$ \\
\hline Zonisamide & $(-)$ & $(-)$ & & $(-)$ & $(-)$ & $\begin{array}{l}\text { Clearance may be increased by } \\
\text { enzyme- inducing AEDs }\end{array}$ \\
\hline
\end{tabular}

This is not meant to be a comprehensive list but represents the most common interactions, based on consensus of panel.

From refs. 4 and 24, with permission.

${ }^{a}$ Monohydroxy derivative (metabolite of oxcarbazepine).

the first or second drug administered. In recent studies, these treatment-responsive patients responded to low doses of essentially all the AEDs studied, both old and new. Although this information can be interpreted as an indication that no new drugs are needed in this patient group, another completely different conclusion can be arrived at. Because these patients will remain with the initial or second therapy for several years, and because they will respond to most drugs, the burden is on the treating physician to select the AED that is the most tolerable and has the lowest potential for harm and the least likelihood of negatively affecting quality of life. At the same time, evidence must be found from valid, well-controlled trials that the drugs are equally as effective as the older medications. The older AEDs have an advantage of broad familiarity, lower cost, known efficacy, wide availability through coverage by third-party payers, and long-term experience. This parameter will review the available evidence on efficacy, tolerability, and safety profiles of the new AEDs in newly diagnosed adults and children with epilepsy. The AEDs are discussed in the order in which they received approval by the FDA. Among these seven new AEDs, the FDA has so far approved OXC for the treatment of new-onset partial epilepsy.

TABLE 3. Comparative pharmacokinetic parameters for new antiepileptic drugs (AEDs)

\begin{tabular}{|c|c|c|c|c|}
\hline AED & $\begin{array}{c}\text { Protein } \\
\text { binding }(\%)\end{array}$ & $\begin{array}{l}\text { Elimination } \\
\mathrm{T}_{1 / 2}(\mathrm{~h})\end{array}$ & Site of elimination & Clinical notes \\
\hline Gabapentin & 0 & $4-6$ & $100 \%$ renal & Displays dose-dependent absorption \\
\hline Lamotrigine & 55 & $15-30$ & $90 \%$ hepatic & $\begin{array}{l}\text { Clearance (via glucuronidation) increased by enzyme-inducing } \\
\text { AEDs; reduced by valproate. Metabolites inactive }\end{array}$ \\
\hline Topiramate & $9-17$ & $15-23$ & $40-70 \%$ renal & $\begin{array}{l}\text { Fraction hepatically metabolized increased by enzyme-inducing } \\
\text { AEDs. Metabolites inactive }\end{array}$ \\
\hline Levetiracetam & 0 & $6-8$ & $\begin{array}{l}66 \% \text { renal. } 34 \% \text { hydrolysis of } \\
\text { acetamide group }\end{array}$ & Metabolism is nonhepatic. Metabolites inactive \\
\hline Oxcarbazepine & 40 & $4-9$ & $70 \%$ hepatic & $\begin{array}{l}\text { Based on 10-hydroxy carbazepine (MHD), the major, active } \\
\text { metabolite }\end{array}$ \\
\hline Tiagabine & 96 & $4-7$ & $98 \%$ hepatic & Oxidative metabolism to inactive metabolites \\
\hline Zonisamide & $40-60$ & $24-60$ & $70 \%$ hepatic & Clearance increased by enzyme-inducing AEDs \\
\hline
\end{tabular}


TABLE 4. Effect of comorbid condition or its treatment on the adverse effects or pharmacokinetics of antiepileptic drugs (AEDs)

\begin{tabular}{lll}
\hline & Older AEDs & Newer AEDs \\
\hline $\begin{array}{l}\text { Metabolic disorder may increase risk } \\
\text { of hepatotoxicity }\end{array}$ & VPA & - \\
$\begin{array}{c}\text { Increased risk of hyponatremia } \\
\begin{array}{c}\text { Clinically important increase in free } \\
\text { fraction with hypoalbuminemia }\end{array}\end{array}$ & PHT & OXC \\
$\begin{array}{c}\text { Metabolism affected by renal disease } \\
\text { Metabolism affected by liver disease }\end{array}$ & PB & - \\
& VPA , PHT, & GBP, LEV, TPM \\
& OXC, TGB \\
\hline
\end{tabular}

VPA, valproic acid; CBZ, carbamazepine; OXC, oxcarbazepine; PHT, phenytoin; PB, phenobarbital; GBP, gabapentin; LEV, levetiracetam; TPM, topiramate; ZNS, zonisamide; TGB, tiagabine.

\section{DESCRIPTION OF THE ANALYTICAL PROCESS}

A literature search was performed including MEDLINE and Current Contents for relevant articles published between January 1987 and September 2001. A second manual search was performed by panel members, covering September 2001 through May 2002. A manual search for class I articles was then updated to include articles published through March 2003. In addition, the Cochrane Library of randomized controlled trials in epilepsy was searched in September 2002, and any appropriate articles identified were added to the review.

\section{Criteria for selection of articles}

The literature search identified all articles that included the terms epilepsy and either gabapentin, lamotrigine, levetiracetam, oxcarbazepine, tiagabine, topiramate, or zonisamide and satisfied the following criteria: (a) Relevant to the clinical questions of efficacy, safety, tolerability, or mode of use; (b) Human subjects only; (c) Types of studies: randomized controlled trials, cohort, case-control, observational, or case series; (d) All languages for randomized controlled trials not available in English; and (e) Relevant to patients with newly diagnosed epilepsy.

\section{Exclusion criteria}

Articles were excluded from further analysis if they were reviews or meta-analyses, articles related to nonepilepsy uses of AEDs unless they described relevant idiosyncratic reactions or safety concerns, and articles on basic AED mechanisms.

A total of 1,462 articles was identified: 240 on GBP, 433 on LTG, 244 on TPM, 17 on LEV, 212 on OXC, 177 on TGB, and 146 on ZNS. Among these, data were extracted for classification of evidence class from 353 articles: 91 on GBP, 63 on LTG, 65 on TPM, 46 on TGB, 45 on OXC, 33 on ZNS, and 11 on LEV. Among these studies were one GBP class I study, three class I or II studies with LTG, two class I studies with TPM, and three class I and one class II studies with OXC in patients with new-onset epilepsy.
We assessed efficacy and dose-related side effects from double-blind controlled studies with $\geq 20$ patients. Safety data also were derived from open trials and case reports.

Data for each AED were reviewed by three panel members, with a different group assembled for each drug. These three panelists classified each article as class I through IV (see Appendix 1). Disagreements on article classification were resolved by discussion and consensus.

\section{Panel selection}

The panel comprised a group of general neurologists, pediatric neurologists, epileptologists, and doctors in pharmacy with experience in pharmacokinetic properties of AEDs. Members did not review a given AED if they had served as advisors for the pharmaceutical company that manufactured the drug and/or if they had been awarded a research grant from that company (participation in multicenter studies was not a reason for exclusion) or if they had financial interests in that company (stock ownership or employee).

\section{NEWLY DIAGNOSED EPILEPSY IN ADULTS AND ADOLESCENTS}

Most studies of newly diagnosed epilepsy are conducted in patients with both partial and generalized seizures, and therefore these are discussed separately unless specific data exist on the individual groups. The majority of these studies defined newly diagnosed epilepsy as two or more untreated seizures. Many compared a new AED with an older AED. This is the only available comparative evidence of new AEDs versus old. Studies of new AED efficacy in the newly diagnosed epilepsy population are typically performed as active-control comparison studies because of the potential risk to subjects inherent in a placebo-controlled monotherapy trial. These studies differ in their methodologies; some studied newly diagnosed patients, some focused on newly treated patients, and the number of seizures before entry may differ. Primary outcome variables differ as well and include end points such as time to exit, time to first seizure, and percentage of patients rendered seizure free. All of these factors can influence response to monotherapy and complicate comparison between studies. Therefore although it appears valid to accept comparisons within a given trial, it is not valid to compare percentage of completers in one trial versus another to determine the most effective drug in newly diagnosed patients. The studies in general are not powered to rule out superiority of one drug over the other. To determine equivalence, very large studies enrolling 500 to 1,000 patients would be required, whereas the studies that were performed typically recruited only 200 to 300 patients. This smaller sample size would lead to confidence intervals that would not exclude a small difference. Furthermore, among all the studies on new-onset epilepsy, no 
study compared the efficacy and safety of the new AEDs among each other.

Question 1: How do the efficacy and tolerability of the new AEDs compare with those of older AEDs in patients with newly diagnosed epilepsy?

\section{Gabapentin}

One study with class I evidence (11) compared the safety and efficacy of three different blinded doses of GBP (300 mg/day, $900 \mathrm{mg} /$ day, and 1,800 mg/day) in monotherapy with that of an open-label fixed dose of immediaterelease CBZ (600 $\mathrm{mg} /$ day) in the treatment of 275 adolescents and adults newly diagnosed with partial or generalized epilepsy. GBP was titrated to its maximal dose in 1 week, and CBZ, in 3 weeks. Patients exited the study if they experienced a total of three simple or complex partial seizures, one generalized tonic-clonic seizure, or status epilepticus. Time to exit was longer for GBP at $1,800 \mathrm{mg} /$ day than at the $300-\mathrm{mg} /$ day dose. No difference was found in the percentage of patients that completed the study among the GBP, 900-mg/day and 1,800-mg/day, groups and the $\mathrm{CBZ}$ group. Discontinuation rate due to adverse events was higher among patients taking CBZ (24\%) than among those taking the higher dose of GBP (13.5\%). Dizziness, fatigue, and somnolence were significantly more frequent among patients with CBZ than with GBP.

\section{Lamotrigine}

Three studies with class I evidence evaluated patients with newly diagnosed idiopathic generalized and partial epilepsy (12-14).

One study (11) compared the efficacy and safety of LTG and an immediate-release formulation of CBZ in 146 patients with new-onset partial seizure disorders and in 122 patients with idiopathic generalized epilepsy. Age range was from 13 to 81 years. Seventy-three patients with partial seizure disorders were randomized to LTG, and 73, to CBZ. Among the patients with idiopathic generalized epilepsy, 60 were randomized to LTG and 62 to CBZ. LTG was started at a dose of $50 \mathrm{mg} /$ day and was titrated up to $150 \mathrm{mg}$ /day over a 4-week period, whereas CBZ was started at $200 \mathrm{mg} /$ day and titrated up to $600 \mathrm{mg} /$ day during the same period. During the last 24 weeks of therapy, the doses of LTG and CBZ could be increased by $50 \mathrm{mg}$ and $200 \mathrm{mg}$, respectively, in case of persistent seizures. Among patients with partial seizure disorders, $48 \%$ of patients taking LTG and $51 \%$ of those taking CBZ remained seizure free during the last 24 weeks of therapy. Among patients with idiopathic generalized epilepsy, $78 \%$ of those taking LTG and $76 \%$ of those taking CBZ remained seizure free. The discontinuation rate was significantly higher among patients taking CBZ (21\%) than taking LTG (11.5\%). The incidence of rash was higher among patients taking CBZ (13\%) than taking LTG (9\%), but this difference did not reach significance.
In a second study (14), the efficacy and safety of LTG were compared among 150 elderly patients (mean age, 77 years) with newly diagnosed epilepsy. In this study, LTG was started at a dose of $25 \mathrm{mg} /$ day for the first 2 weeks, and immediate-release formulation of CBZ at a dose of $100 \mathrm{mg} /$ day. By the end of the sixth week, patients taking LTG took $100 \mathrm{mg} /$ day, and those taking CBZ were treated with $400 \mathrm{mg} /$ day. From week 7 to 24 , the doses could be adjusted to maximal doses of $500 \mathrm{mg} /$ day of LTG and 2,000 mg/day of CBZ. No difference was noted in seizure efficacy between the two drugs. However, a significantly higher number of patients taking CBZ (42\%) had to be discontinued from the study because of adverse events (vs. 18\% for LTG). Furthermore, more patients taking CBZ were discontinued from the study because of rash (19\%) than were those taking LTG $(3 \%)$.

In the third study (13), 86 patients were randomized to LTG, and 95, to PHT. Seizure freedom during the last 24 weeks of therapy was the outcome variable. No difference was found in seizure control between these two drugs, with $43 \%$ of patients taking LTG and 36\% taking PHT remaining seizure free. Among patients with newly diagnosed partial epilepsy, 44 were randomized to LTG, and 46 , to PHT. No difference was seen in seizure-free rates during the last 24 weeks of therapy between the two drugs (45\% for LTG and $46 \%$ for PHT). The discontinuation rate related to adverse events, $15 \%$ for LTG and $19 \%$ for PHT, did not differ either. However, rash accounted for $12 \%$ of the patients taking LTG discontinued from the study, whereas only $5 \%$ of patients taking PHT discontinued because of rash. Altogether, $14 \%$ of patients taking LTG and $9 \%$ of those taking PHT had a rash. The starting dose of LTG in this study was $100 \mathrm{mg} /$ day, which is 4 times higher than the recommended starting dose today. Patients taking PHT had a significantly higher incidence of asthenia ( $29 \%$ vs. $16 \%$ ), somnolence ( $28 \%$ vs. $7 \%$ ), and ataxia (11\% vs. 0$)$.

\section{Topiramate}

Two class I studies were found on the use of TPM in new or recently diagnosed partial or generalized epilepsy $(15,16)$. The first compared the safety and efficacy of $50 \mathrm{mg}$ of TPM $(25 \mathrm{mg}$ if weight $<50 \mathrm{~kg}$ ) versus $500 \mathrm{mg}$ (200 mg if weight $<50 \mathrm{~kg}$ ) in 252 patients aged 3 to 65 years with new or recently diagnosed partial epilepsy (15). Patients had to have experienced one through six partial-onset seizures in the 3-month baseline period. Patients exited the study if they experienced two partialonset seizures, a generalized tonic-clonic seizure if they had no history of that seizure type, or status epilepticus. The two treatment arms did not differ on the primary outcome variable, which was time to exit, although a significant difference was noted in time to second seizure when time to first seizure was used as a simultaneous variable. The second study (16) compared the safety and efficacy 
of TPM at doses of $100 \mathrm{mg} /$ day, $200 \mathrm{mg} /$ day, VPA at $1,250 \mathrm{mg} / \mathrm{day}$, and CBZ at $600 \mathrm{mg} / \mathrm{day}$ in 613 adult and pediatric patients, aged 6 years or older, with newly diagnosed partial and primary generalized epilepsy. Outcome variables included time to first seizure after randomization, time to exit due to lack of efficacy or adverse events, and proportion of seizure-free patients for the last 6 months of treatment. No statistical differences were found in any of the outcome variables between the four treatment groups. The discontinuation rates due to adverse events were $19 \%$ and $28 \%$ for patients in the 100 $\mathrm{mg}$ /day and 200-mg/day TPM arms, respectively; $23 \%$ for those taking VPA; and 25\% for those taking CBZ.

\section{Oxcarbazepine}

Three studies were found with class I and one with class II evidence that compared the efficacy and safety of OXC with that of an older AED (PHT, immediate-release formulation of CBZ, or VPA) in adolescents and adults with newly diagnosed partial seizures and idiopathic generalized epilepsy (17-20).

The first study (17) randomized 287 patients to OXC or PHT. An 8-week flexible titration period yielded OXC doses from 600 to $2,100 \mathrm{mg} / \mathrm{day}(\mathrm{n}=143)$ and PHT at doses ranging between 100 and $560 \mathrm{mg} /$ day $(\mathrm{n}=144)$. One hundred eighty-two patients had a partial seizure disorder, and 104 had primary generalized tonic-clonic seizures. No differences were found in seizure control between the treatment groups, with $59.3 \%$ and $58 \%$ remaining seizure free, respectively, during a 48 -week maintenance period. The rate of discontinuation because of adverse events was significantly higher among patients taking PHT.

The second study (18) compared the efficacy of OXC (600-2,400 mg/day) and VPA (600-2,700 mg/day) in 154 patients with partial seizures and 95 patients with primary generalized tonic-clonic seizures. The variable doses were reached during an 8-week flexible titration period. In the OXC group, $56.6 \%$, and $53.8 \%$ in the VPA group remained seizure free during the maintenance period. No differences were noted between the two drugs with respect to early discontinuation from the study because of adverse events.

The third study (19) compared the efficacy of OXC with that of immediate-release formulation of CBZ in 190 patients with primary generalized tonic-clonic seizures or with secondarily generalized tonic-clonic seizures. A 4- to 8-week flexible titration period yielded OXC doses ranging from 300 to $1,800 \mathrm{mg} /$ day and CBZ doses ranging from 300 to $1,400 \mathrm{mg} /$ day. Sixty percent of patients taking CBZ and 52\% taking OXC remained seizure free. The discontinuation rate due to adverse events was significantly higher among patients taking CBZ (26\%) than OXC (14\%).

The last study (20) compared the efficacy of OXC with that of PHT in 193 children and adolescents aged 5 to
18 years with newly diagnosed partial seizures $(n=151)$ or primary generalized tonic-clonic seizures $(n=39)$. An 8-week flexible titration period yielded OXC doses ranging from 100 to $1,350 \mathrm{mg} /$ day and PHT doses ranging from 100 to $400 \mathrm{mg} / \mathrm{day}$. As in the other studies, the two drugs failed to differ in efficacy, with $61 \%$ and $60 \%$ of patients taking OXC and PHT, respectively, remaining seizure free during the maintenance period. The discontinuation rate was significantly higher for patients taking PHT (14.5\% vs. $2 \%)$.

\section{Conclusion}

Many of these studies resulted in the finding that two drugs were "equivalent" in their ability to control seizures. A great deal of controversy surrounds this outcome. The FDA does not accept such a finding as proof of efficacy because of the possibility that two ineffective drugs might also exhibit no difference in effect when compared against one another. For the purpose of this parameter, we accepted the demonstration of equivalence between an established AED such as CBZ or PHT and a new drug as confirmation of effectiveness.

These studies are able to demonstrate that the new AEDs may be better tolerated than the standard, with equivalent efficacy. However, they cannot speak to the importance of other differences between old and new AEDs, such as simpler pharmacokinetics, absence of apparent disturbance of the hormonal milieu, better safety, and the need for less laboratory monitoring. It is difficult to make such comparisons in an evidence-based fashion. The new drugs are all substantially more expensive than the old. No literature addresses the cost-benefit related to these issues.

\section{Summary of findings}

\section{Efficacy in newly diagnosed patients}

GBP is effective in the treatment of newly diagnosed partial epilepsy. LTG, TPM, and OXC are effective in a mixed population of newly diagnosed partial and generalized tonic-clonic seizures. Insufficient data exist to make a recommendation for the syndromes individually.

Insufficient evidence is found to determine effectiveness in newly diagnosed patients for TGB, ZNS, or LEV.

\section{Comparison with standard AEDs}

OXC is equivalent to CBZ and PHT in efficacy, but superior in dose-related tolerability, at individually determined doses. OXC is equivalent in efficacy and tolerability to VPA. TPM at doses of 100 and $200 \mathrm{mg} /$ day was equivalent in efficacy and safety to 600-mg fixed-dose CBZ and $1,250 \mathrm{mg} /$ day VPA, both in children aged 6 years and older and adults. LTG is equivalent in efficacy to CBZ and PHT and superior in tolerability to CBZ, in both adults and elderly individuals. TPM at 100 and $200 \mathrm{mg}$ is equivalent in efficacy and safety to $600 \mathrm{mg}$ of fixed-dose, immediaterelease $\mathrm{CBZ}$ administered in a b.i.d. regimen for partial 
seizures and to $1,250 \mathrm{mg}$ of fixed-dose VPA for idiopathic generalized seizures.

GBP is effective in monotherapy at 900 and $1,800 \mathrm{mg}$ and is equivalent in efficacy to a $600-\mathrm{mg}$ fixed dose of CBZ. GBP, $900 \mathrm{mg}$, is better tolerated than 600-mg fixeddose, short-acting CBZ administered in a b.i.d. schedule.

\section{Recommendation}

1. Patients with newly diagnosed epilepsy who require treatment can be initiated on standard AEDs such as CBZ, PHT, VPA, PB, or on the new AEDs, LTG, GBP, OXC, or TPM. Choice of AED will depend on individual patient characteristics. (Level A)

Question 2: What is the evidence that the new AEDs are effective in adults or children with primary or secondarily generalized epilepsy?

\section{Lamotrigine}

One study with class II evidence (21) evaluated the efficacy of LTG under double-blind, placebo-controlled conditions in 45 children with newly diagnosed absence seizures. After an open phase trial with LTG (up to 2 to $15 \mathrm{mg} / \mathrm{kg} /$ day), 29 patients became seizure free. These 29 patients were then randomized to remain on LTG or placebo. During the 4 -week study, $64 \%$ of children remained seizure free versus $21 \%$ of children taking placebo. None of the children taking LTG or placebo was discontinued from the study. One child taking LTG had a mild rash. The most frequent adverse events included abdominal pain, headache, nausea, anorexia, and dizziness.

\section{Gabapentin}

One study with class I evidence (22) evaluated the efficacy of GBP monotherapy in 33 children aged 4 to 12 years with newly diagnosed absence seizures in a double-blind, placebo-controlled study of 4 weeks' duration. Children were randomized to GBP at doses of $19 \mathrm{mg} / \mathrm{kg} /$ day (achieved in 2 days) or placebo. No difference was found in seizure frequency between children taking GBP and placebo. None of the children was discontinued from the study. Somnolence and dizziness were the two most frequent adverse events.

No studies in newly diagnosed patients assess the efficacy of OXC, TPM, TGB, LEV, or ZNS in children with exclusively idiopathic or symptomatic generalized epilepsy.

No studies of any new AED assess efficacy/tolerability in adults with newly diagnosed epilepsy with exclusively idiopathic or symptomatic generalized epilepsy.

\section{Conclusions}

LTG is effective in children with newly diagnosed absence seizures.

\section{Summary of findings}

LTG is effective in the treatment of children with newly diagnosed absence seizures. Insufficient evidence exists
TABLE 5. Summary of AAN evidence-based guidelines level $A$ or $B$ recommendation for use

\begin{tabular}{lcc}
\hline Drug & $\begin{array}{c}\text { Newly diagnosed } \\
\text { monotherapy partial/mixed }\end{array}$ & $\begin{array}{c}\text { Newly diagnosed } \\
\text { absence }\end{array}$ \\
\hline Gabapentin & Yes $^{\mathrm{a}}$ & No \\
Lamotrigine & Yes $^{\mathrm{a}}$ & Yes $^{\mathrm{a}}$ \\
Topiramate & Yes $^{\mathrm{a}}$ & No \\
Tiagabine & No & No \\
Oxcarbazepine & Yes & No \\
Levetiracetam & No & No \\
Zonisamide & No & No \\
\hline
\end{tabular}

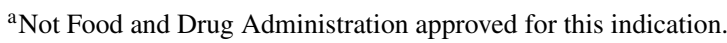

to determine effectiveness in newly diagnosed primary or secondarily generalized epilepsy for TPM, OXC, TGB, ZNS, or LEV.

\section{Recommendation}

1. LTG can be included in the options for children with newly diagnosed absence seizures (Level B).

\section{RECOMMENDATIONS FOR FUTURE RESEARCH}

No doubt the ideal method for detecting drug effect in most cases is to use a placebo control comparison. However, because trials in patients with newly diagnosed epilepsy must be performed, by definition, in the monotherapy condition, ethical concerns exist regarding a placebo or substandard control in this population (23). Therefore comparative trials, although methodologically difficult, remain the preferred tactic. Clinicians favor this trial design, because it mimics clinical care and provides useful information. Because patients are appropriately treated in both arms, often with the ability to adjust dose as necessary, trials can be conducted over long periods ( $\leq 2$ years), and outcome measures can be used that resonate with clinicians, such as percentage of patients remaining seizure free. As noted earlier, these trials are not acceptable for registration purposes in the United States, as the FDA requires demonstration of superiority. To demonstrate superiority, often different doses (low vs. high) of the test drug are used, or in some cases, placebo has been used as the comparator arm. Because the patients in the low dose/placebo arm may be undertreated, trials tend to be shorter and outcome measures not so relevant to practice. In addition, by definition, dose adjustment is not possible. Most important, the absence of a comparison to a standard drug makes the outcome difficult to interpret. Discussion is ongoing as to how to resolve this conflict between the needs of the clinician and the needs of regulatory bodies. Table 5 includes information regarding the difference between the recommendations in this guideline and FDA-approved indications for the drugs addressed in this parameter at the time of its publication. 
We urgently need standardization of trial design and inclusion criteria in active control comparison trials in newly diagnosed patients, where selection of a more stable population could increase the likelihood of a "no difference" outcome, even where a difference actually exists. Similarly, selection of different trial durations and outcome variables can increase the impact of dropouts due to side effects, or bias the outcome in other ways. Selection of standardized design would "even the playing field" for all drugs. Studies should be powered to demonstrate true noninferiority.

No trials have been executed in newly diagnosed patients with any idiopathic generalized syndrome other than absence epilepsy. Comparative trials should be performed in patients with idiopathic generalized tonicclonic seizures and juvenile myoclonic epilepsy, who urgently need more AED options.

Although new AEDs may have some desirable characteristics, they are much more expensive than standard drugs. Future research using economic decision analysis would help to determine whether the potential benefits are worth the additional cost. These would include studies on the clinical importance of hepatic enzyme induction, changes in hormonal milieu, and long-term side effects. Finally, future studies should use extended-release formulations whenever possible.

\section{Disclaimer}

This statement is provided as an educational service of the American Academy of Neurology (AAN). It is based on an assessment of current scientific and clinical information. It is not intended to include all possible proper methods of care for a particular neurologic problem or all legitimate criteria for choosing to use a specific procedure. Neither is it intended to exclude any reasonable alternative methodologies. The AAN recognizes that specific patient-care decisions are the prerogative of the patient and the physician caring for the patient, based on all of the circumstances involved.

APPENDIX 1. Definitions for classification of evidence

\begin{tabular}{ll}
\hline Rating of recommendation & \multicolumn{1}{c}{$\begin{array}{c}\text { Translation of } \\
\text { evidence to recommendations }\end{array}$} \\
\hline $\begin{array}{l}\text { A: Established as effective, ineffective, } \\
\text { or harmful for the given condition in } \\
\text { the specified population }\end{array}$ & $\begin{array}{l}\text { Level A rating requires at least one } \\
\text { convincing class I study or at least } \\
\text { two consistent, convincing class II } \\
\text { studies }\end{array}$
\end{tabular}

B: Probably effective, ineffective, or harmful for the given condition in the specified population

C: Possibly effective, ineffective, or harmful for the given condition in the specified population

$\mathrm{U}$, Data inadequate or conflicting.

Given current knowledge, treatment is unproven
Level B rating requires at least one convincing class II study or at least three consistent class III studies

Level $\mathrm{C}$ rating requires at least two convincing and consistent class III studies
Rating of therapeutic article

Class I: Prospective, randomized, controlled clinical trial (RCT) with masked outcome assessment, in a representative population

The following are required:

a) primary outcome(s) is/are clearly defined

b) exclusion/inclusion criteria are clearly defined

c) adequate accounting for dropouts and crossovers with numbers sufficiently low to have minimal potential for bias

d) relevant baseline characteristics are presented and substantially equivalent among treatment groups or appropriate statistical adjustment is made for differences

Class II: Prospective matched group cohort study in a representative population with masked outcome assessment that meets a-d above OR an RCT in a representative population that lacks one criterion from a to d

Class III: All other controlled trials (including well-defined natural history controls or patients serving as own controls) in a representative population, where outcome assessment is independent of patient treatment

Class IV: Evidence from uncontrolled studies, case series, case reports, or expert opinion

APPENDIX 2. Members of the American Association of Neurology Quality Standards Subcommittee

Gary Franklin, MD, MPH (cochair); Gary Gronseth, MD (cochair); Charles Argoff, MD; Christopher Bever, Jr., MD; Jody Corey-Bloom, MD; John England, MD; Gary Friday, MD; Michael Glantz, MD; Deborah Hirtz, MD; Donald Iverson, MD; David Thurman, MD; Samuel Wiebe, MD; William Weiner, MD; Stephen Ashwal, MD; Jacqueline French, MD; and Catherine Zahn, MD.

Members of the AAN Therapeutics and Technology Assessment Subcommittee are Douglas Goodin, MD (chair); Yuen So, MD (vice-chair); Carmel Armon, MD; Richard Dubinsky, MD; Mark Hallett, MD; David Hammond, MD; Chung Hsu, MD; Andres Kanner, MD; David Lefkowitz, MD; Janis Miyasaki, MD; Michael Sloan, MD; and James Stevens, MD.

Members of the AES Guidelines Task Force are Jacqueline French, MD; Andres Kanner, MD; Mimi Callanan, RN; Jim Cloyd, PhD; Jerome Engel, MD, PhD; Ilo Leppik, MD; Martha Morrell, MD; and Shlomo Shinnar, MD, PhD. 


\section{REFERENCES}

1. Hauser WA, Annegers JF, Kurland LT. Incidence of epilepsy and unprovoked seizures in Rochester, Minnesota: 1935-1984. Epilepsia 1993;34:453-68.

2. Hauser WA, Annegers JF, Kurland LT. Prevalence of epilepsy in Rochester, Minnesota: 1940-1980. Epilepsia 1991;32:429-45.

3. Report of the Quality Standards Subcommittee of the American Academy of Neurology. Practice parameter: management issues for women with epilepsy (summary statement). Neurology 1998;51:4, 944-8.

4. Patsalos PN, Froscher W, Pisani F, et al. The importance of drug interactions in epilepsy therapy. Epilepsia 2002;43:365-85.

5. Isojarvi I, Rattya J, Myllyla V, et al. Valproate, lamotrigine, and insulin-mediated risks in women with epilepsy. Ann Neurol 1998;43:446-51.

6. Morrell MJ, Giudice L, Flynn KL, et al. Predictors of ovulatory failure in women with epilepsy. Ann Neurol 2002;52:704-11.

7. French JA. Long-term therapeutic management of epilepsy. Ann Intern Med 1994;120:411-22.

8. Brodie MJ, French JA. Management of epilepsy in adolescents and adults. Lancet 2000;356:323-9.

9. Kwan P, Brodie MJ. Effectiveness of first antiepileptic drug. Epilepsia $2001 ; 42: 1255-60$.

10. Kwan P, Brodie MJ. Early identification of refractory epilepsy. $N$ Engl J Med 2000;342:314-9.

11. Chadwick DW, Anhut H, Grenier MJ, et al. A double-blind trial of gabapentin monotherapy for newly diagnosed partial seizures: International Gabapentin Monotherapy Study Group 945-77. Neurology 1998;51:1282-8.

12. Brodie MJ, Richens A, Yuen AW. Double-blind comparison of lamotrigine and carbamazepine in newly diagnosed epilepsy: UK Lamotrigine/Carbamazepine Monotherapy Trial Group. Lancet 1995;345:476-9.

13. Steiner TJ, Dellaportas Cl, Findley LS, et al. Lamotrigine monotherapy in newly diagnosed untreated epilepsy: a double-blind comparison with phenytoin. Epilepsia 1999;40:601-7.
14. Brodie MJ, Overstall PW, Giorgi L. Multicentre, double-blind, randomised comparison between lamotrigine and carbamazepine in elderly patients with newly diagnosed epilepsy: the UK Lamotrigine Elderly Study Group. Epilepsy Res 1999;37:81-7.

15. Gilliam FG, Veloso F, Bomhof MAM, et al., and the Topiramate EPMN 104 Study Group. A dose-comparison trial of topiramate as monotherapy in recently diagnosed partial epilepsy. Neurology 2003;60:196-201.

16. Privitera MD, Brodie MJ, Mattson RH, et al. Topiramate, carbamazepine and valproate monotherapy: double-blind comparison in newly diagnosed epilepsy. Acta Neurol Scand 2003;107:16575.

17. Bill PA, Vigonius U, Pohlmann H, et al. A double-blind controlled clinical trial of oxcarbazepine versus phenytoin in adults with previously untreated epilepsy. Epilepsy Res 1997;27:195-204.

18. Christe W, Kramer G, Vigonius U, et al. A double-blind controlled clinical trial: oxcarbazepine versus sodium valproate in adults with newly diagnosed epilepsy. Epilepsy Res 1997;26:451-60.

19. Dam M, Ekberg R, Loyning Y, et al. A double-blind study comparing oxcarbazepine and carbamazepine in patient with newly diagnosed, previously untreated epilepsy. Epilepsy Res 1989;3:70-6.

20. Guerreiro MM, Vigonius U, Pohlmann H, et al. A double-blind controlled clinical trial of oxcarbazepine versus phenytoin in children and adolescents with epilepsy. Epilepsy Res 1997;27:205-13.

21. Frank LM, Enlow T, Holmes GL, et al. Lamictal (lamotrigine) monotherapy for typical absence seizure in children. Epilepsia 1999;40:973-9.

22. Trudeau V, Myers S, LaMoreaux L, et al. Gabapentin in naïve childhood absence epilepsy: results from two double-blind, placebocontrolled, multicenter studies. J Child Neurol 1996;11:470-5.

23. Karlawish JHT, French J. Issues in drug study design: the ethical and scientific shortcomings of current monotherapy epilepsy trials in newly diagnosed patients. Epilepsy Behav 2001;2:193-200.

24. Patsalos PN, Froscher W, Pisani F, et al. The importance of drug interactions in epilepsy therapy. Epilepsia 2002;43:365-85.

25. Sabers A, Buchholt JM, Uldall P, et al. Lamotrigine plasma levels reduced by oral contraceptives. Epilepsy Res 2001;47:151-4. 